\title{
O USO DE TECNOLOGIAS DIGITAIS NA VISÃO DE PROFESSORES EM PROCESSO DE FORMAÇÃO
}

\author{
Yara Emilia Arlindo da Silva ${ }^{1}$ \\ Diene Eire de Mello² \\ Dirce Aparecida Foletto de Moraes ${ }^{3}$
}

Resumo: 0 presente estudo teve por objetivo identificar a percepção de professores em formação sobre 0 uso das tecnologias digitais no processo de ensino e aprendizagem. Trata-se de uma pesquisa de abordagem qualitativa de caráter exploratório, realizada com um grupo de doze estudantes de um Curso de Especialização em Ensino de Ciências Biológicas de uma universidade pública do estado Paraná. Foi utilizado como instrumento de coleta de dados um questionário com questões abertas e fechadas. Adotou-se neste artigo um referencial teórico que nos permitisse analisar as concepções dos participantes a partir de autores como Lévy (1999), Salomon(1992), Cool e Monereo(2010) e Silva (2002; 2010). Constatou-se, por meio da análise dos dados coletados, que os pesquisados apresentam uma concepção de tecnologia ainda muita presa às premissas do passado, considerando como recurso de apoio apenas a fala do professor ou com ênfase no caráter motivacional. Quanto ao uso como ferramenta didática, estes a consideram de grande valia, porém não se sentem integralmente aptos a utilizá-la. Ressalta-se que, apesar dos pesquisados estarem em plena formação, os conteúdos e práticas relativas ao uso das tecnologias não se apresentam como componente curricular no curso em questão, mesmo se tratando de um curso na área de ensino.

Pal avras-Chave: Tecnologias digitais. Ensino. Professor. Ensino de ciências.

${ }^{1}$ Graduada em Biotecnologia, Mestre em Biocências pela UNESP. Especialista em docência na Educação superior.

2 Docente do Departamento de Educação e Programa de Pós-graduação da Universidade Estadual de Londrina. Pedagoga, Mestre em Tecnologia, Doutora em Educação e Pós doutora em Educação com ênfase em E-learning.

${ }^{3}$ Docente do Departamento de Educação da Universidade Estadual de Londrina. Pedagoga, Mestre e Doutora em Educação. 


\title{
THE USE OF DIGITAL TECHNOLOGIES IN THE VIEW OF TEACHERS IN THE TRAINING PROCESS
}

\begin{abstract}
The present study aimed to verify the perceptions of teachers in training on the use of digital technologies in the teaching and learning process. It is a qualitative research of exploratory character, performed with a group of twelve students of a specialization course in Biological Sciences Education of a public University of Paraná State. A questionnaire with open and closed questions was used as a data collection tool. We adopted a theoretical framework that allowed us to analyze the participants' conceptions from authors such as Lévy (1999), Salomon(1992), Cool e Monereo(2010) e Silva (2002; 2010). It was found, through the analysis of the data collected, that the interviewed students have a conception on technology still much attached to the premises of the past, considering as a resource to support just teacher's speech or with emphasis on the motivational feature. As the use as a teaching tool, they considered it to be of great value, but do not feel completely ready to use it. It should be noted that, in spite of the interviewed students are in full training, the contents and practices related to the use of the technologies present themselves as curricular component in such a course, even if in the case of a course in the area of education.
\end{abstract}

Keywords: Digital technologies. Teaching. Teacher. Science teaching.

\section{EL USO DE LAS TECNOLOGÍAS DIGITALES EN LA VISIÓN DE PROFESORES EN FORMACIÓN}

Resumen: Este estudio tuvo por objetivo identificar la percepción de profesores en formación acerca del uso de las tecnologías digitales en el proceso de enseñanza y aprendizaje. Se trata de una investigación de abordaje cual itativo y carácter exploratorio, realizada con un grupo de doce estudiantes del Curso de Especialización en Enseñanza de Ciencias Biológicas de una universidad pública del estado Paraná. Un cuestionario con cuestiones abiertas y cerradas se utilizó como instrumento de recolección de datos. En este artículo se adoptó un referencial teórico que nos permitiera analizar las concepciones de los participantes a partir de autores como Lévy (1999), Salomon (1992), Cool e Monereo (2010) e Silva (2002; 2010). Se constató, por medio del análisis de los dados, que los encuestados presentan una concepción de tecnología aún muy aprisionada a las premisas del pasado, considerando como un recurso de apoyo solamente el habla del profesor, o con énfasis en el carácter motivacional. En cuanto al uso como herramienta didáctica, estos las consideran de gran valor, pero no se sienten integralmente aptos para utilizarla. Se resalta que, a pesar de los encuestados estar en formación, los contenidos y prácticas sobre el uso de las tecnologías no se presentan como componente curricular en el curso en cuestión, aunque si se trata de un curso en el área de enseñanza.

Palabras clave: Tecnologías digitales. Enseñanza. Profesor. Enseñanza de ciencias. 
Introdução

Qual o papel das tecnologias na percepção de professores em formação? As tecnologias possuem potencial para contribuir com a aprendizagem dos estudantes? Estas questões nortearam o presente estudo, que buscou identificar a percepção de professores acerca do uso das tecnologias digitais no processo de ensino e aprendizagem.

Em vários contextos, as tecnologias digitais têm alterado os modos de trabalho, as ações, as relações e formas de comunicação. As mudanças causadas pelo advento das tecnologias digitais são visíveis nos mais variados aspectos de nossas vidas. Pierre Lévy (1999, p. 11) denomina este fenômeno de cibercultura, apontando que estamos vivendo a abertura de um novo espaço de comunicação e que cabe a nós explorarmos as potencialidades mais positivas nos planos econômico, político, cultural e humanos. Para Lemos (2003), cibercultura é a cultura contemporânea marcada pelas tecnologias digitais, sendo consequência direta da evolução da cultura técnica moderna. Assim é possível afirmar que mudanças têm ocorrido em vários âmbitos de nossas vidas provocadas pelas novas formas de comunicação e informação.

Neste cenário, emergem estudos (NICOLACI-DA-COSTA, 2006; TAPSCOTT, 1999; PRENSKY, 2001) acerca de um novo perfil de jovens que nasceram e vivem cotidianamente em uma cultura digital, apontando que são gerações com habilidades e destrezas específicas. Por conseguinte, tais estudos demostram que estes jovens possuem formas diferentes de aprender, diferentemente daqueles que nasceram no mundo analógico.

Entretanto, muitas dessas dinâmicas e alterações não têm se traduzido em exploração das potencialidades de todo aparato presente na cultura digital com a mesma significância nos ambientes acadêmicos. Autores como Sibilia (2012) em sua obra Redes ou Paredes, explora a distância existente entre a escola e a cultura digital, aponta que a escola é um aparelho de época ou máquina antiquada e que seus modos de funcionamento já não se compatibilizam com os jovens do século XXI. Partindo de tal problemática de extrema urgência que as instituições educativas propiciem práticas e dinâmicas que possam ser convergentes com 0 atual cenário da sociedade. Por outro lado, é preciso que as causas justificáveis para o uso de artefatos digitais não sejam 
frágeis a partir de discursos fetichizados. Portanto, o presente estudo teve por objetivo verificar a percepção dos docentes sobre o uso das tecnologias digitais.

\section{Referencial Teórico}

A escola atual tem suas raízes na era industrial, e foi estruturada para disciplinar os trabalhadores, submetê-los a trabalhos repetitivos. Assim, as escolas contavam com um professor por sala, o qual era o detentor da informação e cabia aos alunos realizarem as atividades propostas e serem disciplinados. A organização desse modelo de ensino se baseou nos interesses de uma nova classe que surgia, a burguesia.

0 direito de todos à educação decorria do tipo de sociedade correspondente aos interesses da nova classe que se consolidara no poder: a burguesia. [...] Para superar a situação de opressão, própria do Antigo Regime, e ascender a um tipo de sociedade fundada no contrato social celebrado "livremente" entre os indivíduos, era necessário vencer a barreira da ignorância. [...] A escola é erigida, pois, no grande instrumento para converter súditos em cidadãos. (SAVIANI, 1991, p. 18).

$\mathrm{Na}$ atualidade tem-se uma reconfiguração da sociedade, que passa a ser definida como a sociedade da informação. Assim, os indivíduos são convocados a aprender, a participar ativamente na construção de seu futuro, devido aos novos requisitos de formação de indivíduos, profissionais e cidadãos. 0 progresso da educação, ciência e cultura é fundamentalmente 0 de compartilhar informação e de criar novas possibilidades de aprendizagem e conhecimento (WERTHEIN, 2000).

A evolução tecnológica não diz respeito apenas aos novos usos de determinados aparatos e produtos. Ela modifica comportamentos. 0 homem transita culturalmente mediado pelas tecnologias que Ihe são atuais. E essas transformam sua maneira de viver (KENSKI, 2012).

É possível inferir que a escola em seus diferentes níveis, ainda possui grande ênfase em aulas teóricas, atividades individual izadas, utilizando como principal suporte o texto impresso. Tal aspecto demonstra certa inadequação ao tempo histórico que é mediada pelas mídias online, por meio de dispositivos móveis que podem ser acessados em qualquer tempo e lugar. Os professores que anteriormente tinham como papel principal ensinar, são agora desafiados com novos papéis. 
Numa época designada como era da globalização, os desafios impostos à sociedade não cessam de aumentar e a aprendizagem constitui um tesouro importante para o desempenho profissional de qualquer indivíduo, face às competências profissionais cada vez mais solicitadas. E o campo educacional não é exceção. Atualmente, os docentes são confrontados com novas tarefas, maior profissionalismo, mais responsabilidades e sobre tudo uma panóplia de competências bem diversificadas (CONCEIÇÃO; SOUSA, 2012, p. 82).

Integrar novas práticas pedagógicas por conta das transformações do mundo contemporâneo é um desafio atual para a escola. As tecnologias digitais podem ser utilizadas em sala de aula, na tentativa de modificar o cenário de improdutividade e desprazer, muito observado nos dias atuais nas escolas (LEITE; LIMA; CALDAS, 2014).

Atualmente, os docentes se deparam com um grande desafio e ao mesmo tempo uma oportunidade significativa, utilizar as tecnologias digitais como potencializadoras para construção de conhecimentos. 0 uso dessas tecnologias em sala de aula depende, em parte, da compreensão do docente em relação a esse processo de transformação, se ele compreende esse processo como algo positivo, que pode favorecer o processo de ensino-aprendizagem, ou se ele se sente inseguro e despreparado em relação a essas novas tecnologias (SOUSA; MOITA; CARVALHO, 2011).

Inovar com tecnologias digitais em educação, através de um processo intencional e planejado, significa uma alteração dos processos de ensino/aprendizagem, conduzindo a resultados de aprendizagem efetivos (MEIRINHOS; OSÓRIO, 2015).

Entretanto, é sabido que, para que práticas efetivas sejam consolidadas, faz-se necessário um amplo investimento na formação de professores. Sabe-se nem sempre tal preocupação tenha sido pauta nos programas de formação de professores. Esta problemática reverte-nos para o dilema da formação inicial versus formação continuada. A formação inicial não pode fornecer todos os instrumentos que os professores precisam ao longo de toda a vida profissional. Desta forma, a formação continuada, numa sociedade caracterizada pela desatualização constante, desempenha um papel de atualização permanente, no sentido de desenvolver as competências necessárias para os novos desafios que estão continuamente a surgir (MEIRINHOS; OSÓRIO, 2015).

A educação exigida pela sociedade tecnológica requer indivíduos que sejam interlocutores e participantes do processo, discentes que saibam utilizar os recursos disponíveis para solucionar problemas, agir e produzir novos conhecimentos (MACHADO; KAMPFF, 2017). 
É preciso compreender as tecnologias digitais como instrumentos mediadores da aprendizagem, que permita articular e potencializar a construção do conhecimento, desenvolvendo assim, novas formas de pensar que repercutam significativamente nos processos de ensino e aprendizagem. É fundamental elucidarmos de que maneira percebemos o papel das tecnologias no processo de ensino. A partir de autores como Lévy (1999), Coll, Mauri e Onrubia (2010), Salomon (1992), e Silva (2010) são aqui entendidas como ferramentas de pensamento, não apenas instrumentos que ilustram a fala do professor no trato do conceito científico a ser explorado pela aula expositiva do professor. As TIC devem ser entendidas a partir das ideias Vygotskiana como instrumentos psicológicos de pensamento e de interpensamento (COLL; MAURI; ONRUBIA, 2010, p. 88).

As práticas de ensino e os desenhos didáticos de cursos e disciplinas precisam potencializar a comunicação e a aprendizagem e não subutilizar as interfaces online destinados a possibilitar agregações, associações e significações como autoria e coautoria aos estudantes (SILVA, 2010).

Assim entendidas, as tecnologias não são somente simples artefatos a que estamos expostos de forma passiva, mas um conjunto de ferramentas com as quais os indivíduos atuam de forma interativa (SALOMON, 1992). Dito isso, o presente estudo parte de uma concepção de tecnologia que contribui para ampliação de pensamento, memória, análise e crítica, devendo a mesma ser vista como parte da cultura acadêmica, não mero adereço ou recurso que não altera as condições de transmissão e recepção das salas de aula em que o foco permanece no professor.

Entretanto, estudos já realizados por pesquisadores como Almeida e Valente (2011), Kenski (2012) e Mello, Moraes e Barros (2017), no campo das tecnologias tem demonstrado que não basta apenas investir em tecnologias e artefatos, sem que estes sejam acompanhados de uma formação adequada, que leve em conta tanto a realidade dos professores, quanto o local de atuação dos mesmos.

\section{Procedimentos Metodológicos}

0 presente estudo, trata de uma pesquisa qualitativa de caráter exploratório. Utilizou-se como instrumento de coleta de dados, um questionário com 15 (quinze) questões, sendo 6 (seis) abertas e 9 (nove) fechadas. Foram participantes desse estudo, 
professores em processo de formação de um Curso de Especialização em Ensino de Ciências Biológicas de uma universidade pública do Paraná no ano de 2016. A escolha dos participantes se deu por conveniência. A turma era composta por catorze alunos, ao todo, doze alunos responderam ao instrumento. Cada participante foi codificado de acordo com a sua idade e tempo de experiência no magistério. Os participantes foram identificados por números (1 a 12), pela idade e anos de experiência como professor. Ex: E1.32a.9e.

0 curso, que fora campo deste estudo, tem por objetivo formar professores de ciências e biologia para a escola básica, por meio de disciplinas e atividades teóricopráticas. 0 mesmo tem duração de 360 horas (trezentas e sessenta), correspondentes a vinte e quatro créditos desenvolvidos em dois períodos letivos.

A especialização oferece doze disciplinas de trinta horas e elaboração da monografia. Salienta-se que todos os participantes do estudo são licenciados, ou seja, tiveram na formação inicial, conteúdos relacionados ao fazer docente.

\section{Resultados e Discussões}

Retomando aqui o objetivo do presente estudo, que foi verificar a percepção dos docentes sobre 0 uso das tecnologias digitais, pautamo-nos na análise das respostas dos professores participantes.

Os dados obtidos permitiram constatar que em relação ao perfil dos participantes da pesquisa, observou-se um público relativamente jovem, com idade média de 28 anos (vinte e oito) e em sua grande maioria do sexo feminino.

De acordo com dados do Censo do Professor, na educação infantil e no ensino fundamental I, o universo docente é predominantemente feminino $(98 \%, 96 \%$ e $91 \%$, respectivamente). Não obstante, se consideradas todas as etapas e modalidades da educação básica, 81,6\% dos professores que estavam em regência de classe são mulheres e somam mais de um milhão e meio de docentes. 0 professor "típico" no Brasil é do sexo feminino, de nacionalidade brasileira e tem 30 anos de idade (BRASIL, 2009).

Todos os participantes possuem formação em Ciências Biológicas. A maioria destes concluiu recentemente 0 curso (nos últimos 5 anos). Os quadros 1 e 2 apresentam 0 tempo de formação, o número de participantes formados em instituições públicas e privadas e os estados em que esses se formaram: 
Quadro 1 - Tempo de formação dos pesquisados

\begin{tabular}{|c|c|c|}
\hline $\begin{array}{c}\text { Graduados nos } \\
\text { últimos } 5 \text { anos }\end{array}$ & $\begin{array}{c}\text { Graduados nos } \\
\text { últimos } 10 \text { anos }\end{array}$ & $\begin{array}{c}\text { Graduados há mais } \\
\text { de } 10 \text { anos }\end{array}$ \\
\hline $50 \%$ & $33 \%$ & $17 \%$ \\
\hline
\end{tabular}

Fonte: Elaborado pelas autoras.

0 quadro 1 demonstra que 0 grupo é bastante heterogêneo em relação ao tempo de formação. Tal aspecto demostra que após um tempo de término da graduação há uma busca pela formação continuada.

Quadro 2 - Instituições
\begin{tabular}{|l|l|l|}
\hline Universidades & Paraná & São Paulo \\
\hline Públicas & 5 & - \\
\hline Privadas & 6 & 1 \\
\hline
\end{tabular}

Fonte: Elaborado pelas autoras.

Dos 12 (doze) participantes, apenas 3 (25\%) já haviam cursado outros cursos de pós-graduação (lato sensu), na área da educação e meio ambiente.

Apenas metade dos pesquisados (50\%) atua como docente. Tal aspecto pode sugerir que, em relação ao curso de Ciências Biológicas, os alunos ao ingressarem não desejam seguir a área de docência, porém após a formação se torna um dos caminhos de mais fácil acesso ao mercado de trabalho no campo de biológicas, sendo a docência a segunda opção. De acordo com pesquisa de Louzano, Rocha, Moriconi e Oliveira (2010), os professores, em média, recebem salários mais baixos do que outros profissionais, tanto no setor público como no privado. A essa baixa remuneração soma-se o baixo status social da carreira e poucas oportunidades de influenciar as políticas públicas, em especial as que afetam o trabalho docente em sala de aula.

No Brasil, os cursos de licenciatura, são constituídos por alunos com perfil socioeconômico baixo. Professores com até dois anos de experiência ganham menos do que seus pares em outras profissões nos setores públicos e privados. Além de salários iniciais pouco atrativos, a carreira não parece promissora no longo prazo, outras ocupações que não o ensino são, mais vantajosas financeiramente (LOUZANO et al., 2010). Esses fatores somados à falta de infraestrutura e capacitação justificam a baixa atratividade na carreira docente.

De acordo com pesquisa de Cerqueira e Cardoso (2010) que analisou a relação entre expectativas profissionais e concepções em torno da docência para licenciandos 
em Ciências Biológicas, identificaram uma tendência exclusiva para a área de pesquisa no bacharelado, apesar de estarem cursando a licenciatura, só admitindo a docência em nível superior. Porém, após a conclusão do curso, muitos não encontram oportunidades de atuar no ensino superior, e optam por lecionar na educação básica. Muitos se encontram em conflito antes e durante a vida profissional, bem antes de se reconhecerem como docentes passam pelo estágio de reconhecimento pessoal até se definirem profissionalmente.

Considerando que o grupo participante deste estudo optou por ingressar na Especialização em Ensino de Ciências Biológicas, parte-se da hipótese que estão em busca de qualificação, procurando investir em sua formação profissional no campo da educação. Por outro lado, os dados coletados apontam que apenas 6 participantes (50\%) atuam como docentes, na rede pública estadual, no segundo ciclo do ensino fundamental ou ensino médio.

Em relação ao foco de estudo que trata de uso de tecnologias, foi-Ihes questionado se faziam o uso de artefatos e aplicativos no cotidiano (Quadro 3), obtivemos o seguinte resultado:

Quadro 3- Utilização de artefatos e aplicativos

\begin{tabular}{|l|l|}
\hline $\begin{array}{l}\text { Artefatos e seus } \\
\text { programas }\end{array}$ & $\begin{array}{l}\text { № de professores } \\
\text { que fazem uso }\end{array}$ \\
\hline Celular & 12 \\
\hline Computadores & 12 \\
\hline Tablets & 2 \\
\hline E-mail & 12 \\
\hline Facebook & 10 \\
\hline Twiter & 1 \\
\hline Blog & 1 \\
\hline Fotolog & 0 \\
\hline Google drive & 5 \\
\hline Power point & 12 \\
\hline Amaze & 0 \\
\hline Prezi & 1 \\
\hline Editores de texto & 10 \\
\hline Editores de imagem & 10 \\
\hline Fonte: Elaborado pelas autoras.
\end{tabular}


Todos os participantes afirmaram que fazem uso de tecnologias digitais no cotidiano. Porém, nem todos fazem uso de artefatos e aplicativos que podem ser utilizados na educação, na tentativa de ampliar as possibilidades dos alunos se envolverem com o conteúdo. De acordo com dados CETIC - TIC Domicílios - (2017), 46\% dos domicílios possuem computador, sendo que apenas 29\% apresentam computador portátil e 17\% tablets. Em relação a domicílios com acesso à internet, 54\%. Já 93\% dos domicílios apresentam telefone celular (CETIC, 2017).

Esses dados corroboram com a realidade dos pesquisados, já que todos utilizam celulares e computadores no dia-a-dia. Os dados revelam que os participantes fazem uso de artefatos no cotidiano. Ou seja, não são objetos estranhos, fazem parte da cultura dos mesmos.

Observou-se que 10 participantes (83\%) fazem uso de redes sociais no cotidiano. Considerando que os mesmos acessam com frequência o facebook, levanta-se aspectos importantes no sentido de utilização das redes sociais no processo de ensino e aprendizagem.

O gráfico 1 retrata a autopercepção dos pesquisados, quanto ao uso pessoal das tecnologias digitais.

Gráfico 1 - Uso pessoal de tecnologias digitais

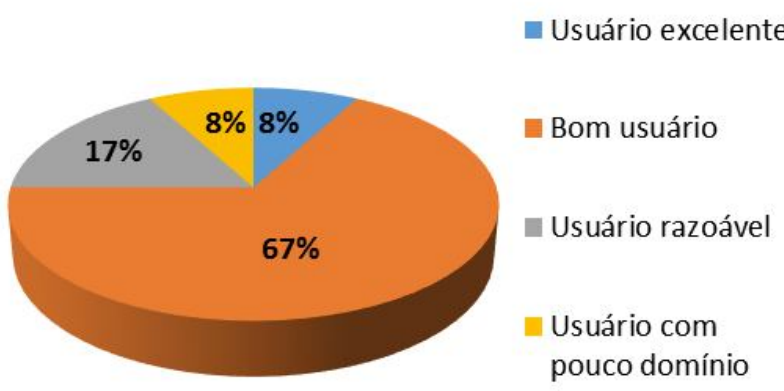

Fonte: Elaborado pelas autoras.

Em relação ao uso pessoal, 8 pesquisados (67\%) se consideram bons usuários. E apenas 1 pesquisado (8\%) afirmou fazer o uso das tecnologias digitais de forma efetiva. Levando em consideração o Quadro 1, constata-se que de acordo com a resposta dos pesquisados, bom usuário é aquele que domina os artefatos e programas mais comuns, 
já que aqueles menos convencionais (tablet, blog, prezi, etc) foram assinalados pela minoria dos docentes.

De acordo com pesquisa de Neri (2012), verificou-se que a população mais jovem percebe com maior frequência a incorporação de novas tecnologias no seu ambiente de trabalho. A dificuldade para com seus usos é maior para a população com mais de idade. Entre os indivíduos de 25 a 30 anos, apenas $12,42 \%$ apresentam dificuldade na adequação a essas novas tecnologias.

Importante salientar que o interesse no estudo era identificar a percepção de professores em formação em relação as tecnologias. Desta forma, considera-se de suma importância as experiências que os participantes tiveram a longo do ensino superior com artefatos tecnológicos para aprender. Há defasagem clara entre o nível de comodidade que sentem os alunos e o que sente o professorado frente as TIC. Em geral, os alunos têm um sentimento de autocompetência significativamente mais alto que 0 professorado (COLL; MAURI; ONRUBIA, 2010, p. 67).

Em relação a sua formação no ensino superior, apenas 4 (33\%) afirmam que tiveram alguma disciplina ou conteúdo que tratasse do uso das tecnologias em sala de aula, porém de uma forma superficial. Tal aspecto revela que apesar das diferentes mídias e artefatos estarem presentes no cotidiano da maioria das pessoas, estas ainda não fazem parte do cotidiano das licenciaturas.

Em relação a este aspecto, importante refletirmos acerca do uso ainda esporádico de tecnologias nos processos de ensino. Mesmo quando se dispõe de equipamento e de uma infraestrutura que garanta acesso às $\mathrm{TIC}$, professores e alunos frequentemente fazem uso limitado e pouco inovador (COLL; MAURI; ONRUBIA, 2010, p. 74).

Essa carência nos currículos de licenciatura, dificulta o emprego das mesmas em suas práticas pedagógicas de forma didática. Considerando os avanços tecnológicos e a relevância da util ização de tecnologias em sala de aula, a formação desses profissionais se apresenta em dissonância com 0 atual contexto da sociedade mediada pelas tecnologias digitais.

De maneira geral, nas licenciaturas, as tecnologias não têm sido tratadas como componente curricular, ou quando aparecem, são tratadas de maneira superficial, pois a formação desses profissionais se dá a partir de embasamentos teóricos, não relacionando a prática com a real função das tecnologias na educação (MARINHO, 
2008). Apesar de vivermos em uma sociedade mediada pelas tecnologias da informação, grande parte dos professores é proveniente de uma sociedade analógica que precisa ensinar de uma forma que não condiz com a forma que foi ensinada. Esses profissionais precisam de investimento em sua formação profissional e pessoal. Dessa forma, é essencial que haja melhoria na qualificação dos processos e práticas direcionadas à formação do educador (J ENICHEN, 2014).

De acordo com os dados CETIC - TIC EDUCAÇÃO (2016), 92\% dos professores do país fazem uso de internet no celular, porém apenas 39\% utilizam internet nesse dispositivo móvel para desenvolver atividades com os alunos. Apenas $14 \%$ dos professores levam seus tablets para a escola e 46\% o computador portátil. Em relação à internet: acesso sem fio e restrições para uso, em 16\% das escolas privadas, todos, inclusive alunos, não possuem acesso ao Wi- $\mathrm{Fi}$, enquanto nas escolas públicas apenas $6 \%$; em $58 \%$ o uso é restrito/com senha e os alunos não tem acesso, já nas escolas públicas $62 \%$; em $19 \%$ o uso é restrito/com senha, porém o aluno tem acesso, enquanto nas escolas públicas $16 \%$; e apenas $6 \%$ não possuem Wi-Fi, já nas escolas públicas $16 \%$ (CETIC, 2016).

0 mesmo estudo também verificou que $39 \%$ dos professores tiveram disciplinas específicas na graduação sobre como usar computador e internet em atividades com alunos. Na região sudeste, apenas $33 \%$ das escolas ofereceram palestras ou cursos sobre o uso responsável da internet, já na região sul 32\% das escolas (CETIC, 2016).

Um conteúdo didático de qualidade em formato digital não será de grande valia, se os estudantes não forem capazes de utilizar as tecnologias digitais pedagogicamente. É válido lembrar que para que as tecnologias digitais tenham um papel significativo no processo de ensino e aprendizagem, o professor, além de receber capacitação, precisa se planejar, compreender a essência dessas ferramentas e as necessidades crescentes nesse processo. Para novas ferramentas também são necessários novos métodos (BARROS, 2013, p. 30).

A utilização de tecnologias digitais no ensino tem potencial para aproximar a escola do universo do aluno, já que este, na maioria das vezes, tem acesso desde a infância a vários dispositivos móveis. 0 uso efetivo das tecnologias digitais pode contribuir para promover uma aprendizagem mais substancial, desenvolver o raciocínio lógico, a criatividade e estimular o trabalho em equipe. 
O gráfico a seguir mostra a porcentagem de professores que estão aptos para utilizar as diferentes tecnologias digitais em sala de aula.

Gráfico 2 - Percepção dos professores em relação aos artefatos

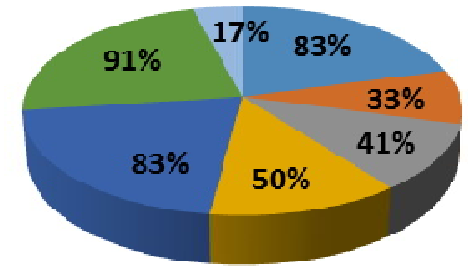

$$
\begin{aligned}
& \text { - Laboratório de informática } \\
& \text { n Lousa digital } \\
& \text { —Tablets }
\end{aligned}
$$

- Plataformas de ensino

n Celular

- Projetor multimídia

$\varpi T V$ pen drive

Fonte: Elaborado pelas autoras.

Apesar da grande maioria se considerar bom usuário de tecnologia, eles não se sentem aptos para utilizar todas as tecnologias digitais apontadas no instrumento em questão. Dado este, que nos revela um problema a ser enfrentado pelas universidades, pois o processo de formação de professores inicia-se nos primeiros anos, quando o futuro professor recebe preparação nas instituições de ensino. A formação inicial é o início da construção do "eu professor", que vai avançando para novos estádios profissionais através da formação continuada, assim se constrói ou reforça a identidade profissional, que se constitui de vários aspectos: conhecimentos teóricos, práticos, a relação desse profissional com o meio em que vive, sua postura mediante a sala e as estratégias utilizadas na aula (MARTINEZ; LEITE; MONTEIRO, 2015). Assim, uma formação inicial de qualidade com enfoque no uso pedagógico das tecnologias digitais e investimento em formação continuada permitirá que esses profissionais sejam verdadeiros mediadores e agentes propagadores de novas formas de pensar, que possibilitam de fato uma aprendizagem mais efetiva.

Um dado importante, revelado é que apesar de não se sentirem aptos, todos os participantes do estudo acreditam que o uso de tecnologias ajuda no processo de ensino e aprendizagem. No quadro a seguir consta a opinião de cada um deles em relação a essa questão. 
Quadro 4 - Importância do uso de TDs

\begin{tabular}{|c|c|}
\hline A importância do uso de TDs no processo de ensino e aprendizagem & $\begin{array}{l}\text { Participante } \\
\text { S da } \\
\text { pesquisa }\end{array}$ \\
\hline $\begin{array}{l}\text { Alguns conteúdos são mais difíceis para o aluno compreender, ou } \\
\text { não tem esse conteúdo no livro didático, ou outra forma de pesquisá-lo, e } \\
\text { o uso de tecnologias pode colaborar com a aprendizagem. }\end{array}$ & E1.32a.9e. \\
\hline $\begin{array}{l}\text { Acredito que possibilita a melhor visualização, contextualização e } \\
\text { assimilaçãao dos conteúdos, principalmente quando são utilizados vídeos, } \\
\text { gifs ou animações. }\end{array}$ & E2.29a.3e. \\
\hline $\begin{array}{l}\text { Acredito que auxilia no processo de ensino-aprendizagem, pois a } \\
\text { sociedade está imersa em recursos tecnológicos e levar isso para a sala } \\
\text { de aula, aproxima o ensino da realidade do aluno. }\end{array}$ & E3.30a.0,5e \\
\hline $\begin{array}{l}\text { A tecnologia pode auxiliar a aprendizagem e torná-la atrativa para } 0 \\
\text { aluno. }\end{array}$ & E4.23a.0e. \\
\hline $\begin{array}{l}\text { Sim, porque é importante se adequar ao dia-a-dia do aluno e hoje } \\
\text { em dia, os jovens são muito interessados por tecnologias. Por isso, acho } \\
\text { importante unir a tecnologia com o ensino. }\end{array}$ & E5.27a.0e. \\
\hline $\begin{array}{l}\text { As tecnologias atraem a atenção do aluno por ser algo diferente, } \\
\text { além de dar um conceito visual que facilita a aprendizagem. }\end{array}$ & E6.23a.0e. \\
\hline $\begin{array}{l}\text { Sim, facilita a busca por informações em tempo real, discussão em } \\
\text { grupo, é dinâmico e estimula a aprendizagem entre professores e alunos. }\end{array}$ & E7.45a.0e. \\
\hline $\begin{array}{l}\text { Possibilita um recurso audiovisual, en riquece com detalhes sobre } 0 \\
\text { tema trabalhado, aumenta o interesse da turma. }\end{array}$ & E8.32a.8e. \\
\hline $\begin{array}{l}\text { Sim, pois as tecnologias estão cada vez mais inseridas na realidade } \\
\text { dos alunos, podendo despertar um maior interesse e também diversificar } \\
\text { o método de ensino. }\end{array}$ & E9.25a.1e. \\
\hline Pois facilita tanto a vida do professor, quanto do aluno. & E10.22a.0e. \\
\hline $\begin{array}{l}\text { Os alunos evoluiram, cabe ao professor não ficar parado no tempo e } \\
\text { buscar cada vez mais novas ferramentas, para chamar a atenção dos } \\
\text { alunos, despertar a vontade do querer saber, e as novas tecnologias estão } \\
\text { presentes para serem utilizadas em sala de aula. }\end{array}$ & E11.27a.0e. \\
\hline $\begin{array}{l}\text { Porque auxilia o entendimento do aluno, tanto no aspecto visual, } \\
\text { auditivo e outros. }\end{array}$ & E12.26a. \\
\hline
\end{tabular}

Fonte: Elaborado pelas autoras.

Os participantes por meio de pergunta aberta, explicitaram diferentes concepções acerca dos usos de tecnologias conforme o quadro acima. De acordo com Fagundes (2012), a tecnologia não é feita somente para ser usada, por exemplo, em uma aula com 
slides em Power point. 0 bom uso tecnológico consiste em mudar os paradigmas da educação do sentido analógico. A tecnologia serve para despertar o funcionamento da inteligência, o pensamento reflexivo, para fazer pesquisa, despertar o desejo de aprender mais e aumentar a autoestima do aluno. Os estudantes precisam usar as tecnologias digitais para melhorar a reflexão, o juízo crítico e alcançar autonomia.

Porém, de acordo com os dados coletados, permite-se inferir que estes apresentam ainda uma de concepção de tecnologia dos anos 80 como recurso, apoio, a fala do professor, colaboram, atraem, ilustram, ou seja, atribuindo caráter motivacional e de suporte ao ensino. Ou seja, estas não são vistas como artefatos para pensar, analisar, construir, dando autoria ao aluno, como protagonista de sua aprendizagem. Os grifos ressaltam as palavras que descrevem a função da tecnologia, o que ela permite, faz ou sugere. Se analisarmos mais profundamente, a falas do quadro acima, é possível perceber que tais percepções estão ainda ancoradas em um referencial que não se coaduna com os artefatos da atual idade e suas potencialidades pois ase apresentam com ênfase na motivação, no interesse, na ilustração e no apoio. Nenhum professor se aproxima dos aspectos ligados ao desenvolvimento cognitivo propriamente dito ou implicações do artefato no desenvolvimento cognitivo. Neste sentido, Salomon (1992) considera que a mediação e interação que ocorre de diferentes maneiras pode influenciar a capacidade mental também de formas variadas, seja por meio da relação direta com o artefato ou ainda por um processo de internalização da sua representação cultural. 0 autor aponta que ao fazer uso dos artefatos em suas tarefas, o aprendiz será levado a realizar atividades com alto nível de habilidades cognitivas e não tarefas mecânicas.

Observa-se ainda no quadro 4, que os participantes percebem as tecnologias como sinônimos de inovação, modernização e que aproximam a escola da realidade do aluno, como se o simples uso das mesmas desencadeasse automaticamente processos inovadores em salas de aula. É possível inferir que parte-se de uma concepção baseada no senso comum.

As tecnologias são instrumentos de pensamentos que estão inseridas no ensino em função de suas características, funcionalidades e das práticas culturais que enquanto grupo social desenvolvemos com elas, nos permitem visualizar, conhecer e experimentar fenômenos de formas diferentes apresentando o conhecimento por outra ótica. 
Refletindo, assim, na produção de novos conhecimentos. É relevante que se perceba a função dessas tecnologias como instrumento de pensamento que intervém sobre a comunicação, percepção e estratégias cognitivas (PASSERINO, 2010).

0 uso efetivo das tecnologias digitais diz respeito à utilização destas como instrumento de colaboração e compartilhamento de informação através da formação de redes e não apenas de treinar a equipe docente para consumir produtos tecnológicos (CARVALHO, 2011).

É necessário repensar o que é ensinar e aprender, para que existam transformações expressivas nos processos educativos. Assim, as escolas inseridas no contexto da cultura digital, assumem um papel significativo na formação dos discentes, pois podem oportunizar múltiplos espaços de aprendizagem e ampliar as possibilidades de encontros virtuais e de interação, instigando a cooperação e a produção colaborativa do saber (MACHADO; KAMPFF, 2017).

Considerando que o docente é o mediador do conhecimento e tem papel chave na formação de cidadãos, é indispensável ouvir esses profissionais sobre suas percepções em relação às tecnologias. Para então, promover reflexões sobre essa temática, dando ênfase ao caráter pedagógico dessa. Que deve ser trabalhada nas licenciaturas e em cursos de capacitação oferecidos pelas escolas, para favorecer o desenvolvimento global dos estudantes (CEZAROTTO; RÜCKL; BRITO, 2017).

\section{Considerações Finais}

0 presente estudo, que teve por objetivo verificar a percepção de professores em formação sobre o uso das tecnologias digitais no processo de ensino e aprendizagem. A partir da análise dos dados coletados, identificou-se que os participantes são relativamente jovens, do sexo feminino, em sua grande maioria, professores da rede estadual e particular, que fazem o uso das tecnologias digitais no dia-a-dia. Porém, quanto ao uso como ferramenta didática, não se sentem integralmente aptos, pois em suas formações, em sua grande maioria, não tiveram disciplinas ou conteúdos relacionados à utilização dessas tecnologias em sala de aula. Tal dado, nos leva a refletir acerca da necessidade de currículos organizados a partir dos cenários sociotécnicos vivenciados por crianças e jovens. 
Consideramos importante sinalizar que os resultados aqui apresentados fazem parte de um contexto específico. Por outro lado, estes dados lançam luz a uma problemática que precisa ser enfrentada pelas instituições de ensino que formam professores. Não se trata de adequar currículos ou inserir uma disciplina que tenha como foco reflexões e práticas no campo das tecnologias digitais e aprendizagem. É preciso que futuros professores vivenciem experiências exitosas ao longo de sua formação que permita conhecer, explorar, criar e analisar práticas educativas que levem em conta o contexto da cibercultura.

Como consequência da escassez de experiências didáticas mediada pelas tecnologias, a análise das respostas nos permitem perceber um caráter meramente instrumental das tecnologias e por vez motivacional. Tal aspecto se reveste de uma problemática crucial para a formação de futuros professores. As reflexões aqui realizadas apontam para a necessidade de uma formação no campo das tecnologias que promova novas formas de ensinar, para a promoção de uma aprendizagem mais substancial, contribuindo assim para novas formas de pensar.

Além disso, as respostas subjetivas revelam uma visão bastante comum acerca das tecnologias como sinônimo de inovação, tendo a escola de "adequar-se" a realidade vigente. Tal aspecto tem sido usado como justificativas para investimentos no campo das tecnologias em instituições de ensino. Ou seja, basta o simples uso das tecnologias que as práticas de ensino sejam inovadoras. Importante se faz, refletir: para que servem as tecnologias em sala de aula? 0 que estas propiciam aos estudantes? Tais reflexões são de grande importância no sentido de não atribuir às tecnologias visões fetichizadas, e ao mesmo tempo, estereotipadas. Nesse sentido, reforçamos a ideia das tecnologias como ferramentas de pensamento, que possibilitam a criação, co-criação, partilha, análise, reflexão e autorias por parte do educando.

Importante salientar, as limitações do presente estudo, pois lançou-se mão de apenas um instrumento de coleta de dados, com um pequeno grupo de professores em formação. Seria de grande valia, estudos mais aprofundados com entrevistas e acompanhamento de professores em exercício. Outros estudos podem ser realizados com outros públicos e outros instrumentos de coleta de dados, na tentativa de compreender a percepção dos docentes em relação a essa temática e a importância e os desafios da 
inserção nos currículos dos cursos superiores e aplicação efetiva das tecnologias digitais na sala de aula, como instrumento mediador da construção do conhecimento.

\section{Referências}

A TECNOLOGIA serve para despertar o funcionamento da inteligência, diz especialista em educação digital. Pioneiro, Caxias do Sul, 1 dez. 2012. Caderno Educação. Disponível em: http:// pioneiro.clicrbs.com.br/rs/geral/cidades/noticia/2012/12/a-tecnologiaserve-para-despertar-o-funcionamento-da-inteligencia-diz-especialista-em-educacaodigital-3968190.html. Acesso em: 27 mar. 2018.

ALMEIDA, M. E. B.; VALENTE, J. A. Tecnologias e currículo: trajetórias convergentes ou divergentes. São Paulo: Paulus, 2011.

BARROS, D. M. V. EAD, tecnologias e TIC: introduzindo os aspectos didáticos e pedagógicos do tema. In: YONEZAWA, W. M.; BARROS, D. M. V. (org.). EAD, tecnologias e TIC. São Paulo: Cultura Acadêmica; Marília: Oficina Universitária, 2013. p. 35-49. Disponível em: https:// www.marilia.unesp.br/Home/Publicacoes/af-livro_12__barrosV2.pdf. Acesso em: 3 jan. 2017.

BRASIL. Ministério da Educação. Estudo exploratório sobre o professor brasileiro com base nos resultados do Censo Escolar da Educação Básica 2007. Brasília: Inep, 2009. Disponível em: http://portal.mec.gov.br/dmdocuments/ estudoprofessor.pdf. Acesso em: 8 mar. 2017.

CARVALHO, A. B.; ALVES, T. P. Apropriação tecnológica e cultura digital: o programa "Um computador por aluno" no interior do nordeste brasileiro. Logos: Comunicação e Universidade, Rio de J aneiro, v. 18, n. 1, p. 88-101, 2011. Disponível em: https://www.epublicacoes.uerj.br/index.php/logos/article/view/1250/1598. Acesso em: 15 jan. 2017.

CERQUEIRA, S. V. S.; CARDOSO, L. R. Biólogo-professor: relação entre expectativas profissionais e concepções em torno da docência para licenciandos em Ciências Biológicas. Contexto e Educação, ljuí, v. 25, n. 84, p. 143-160, jul./dez. 2010.

CETIC - CENTRO DE ESTUDOS SOBRE AS TECNOLOGIAS DA INFORMAÇÃO E DA COMUNICAÇÃO. Pesquisa sobre o uso das Tecnologias de Informação e Comunicação no Brasil. São Paulo: CETIC, 2017. Disponível em:

http://cetic.br/media/analises/tic_domicilios_2016_coletiva_de_imprensa.pdf. Acesso em: 12 jan. 2018.

CETIC - CENTRO DE ESTUDOS SOBRE AS TECNOLOGIAS DA INFORMAÇÃO E DA COMUNICAÇÃO. TIC Educação 2015: apresentação dos principais resultados. São Paulo: CETIC, 2016. Disponível em: http://cetic.br/media/analises/tic_educacao_2015_coletiva_de_imprensa.pdf. Acesso em: 14 jan. 2018. 
CEZAROTTO, M. A.; RÜCKL, B. F. N.; BRITO, G. S. A percepção dos professores em relação ao termo tecnologia. In: CONGRESSO NACIONAL DE EDUCAÇÃO, 13., 2017, Curitiba. Anais [...]. Curitiba: PUCPR, 2017. p. 2540-2553. Disponível em: http://educere.bruc.com.br/arquivo/pdf2017/26879_13654.pdf. Acesso em: 8 mar. 2018.

COLL, C.; MAURI, T.; ONRUBIA, J. A incorporação das tecnologias de informação e da comunicação na educação: do projeto técnico-pedagógico às práticas de uso. In: COLL, C.; MONEREO, C. (org.). Psicologia da educação virtual: aprender e ensinar com as Tecnologias da Informação e da Comunicação. Porto Alegre: Artmed, 2010. p. 66-93.

COLL, C.; MONEREO, C. (org.). Psicologia da educação virtual: aprender e ensinar com as Tecnologias da Informação e da Comunicação. Porto Alegre: Artmed, 2010.

CONCEIÇÃO, C.; SOUSA, O. Ser professor hoje: 0 que pensam os professores das suas competências. Revista Lusófona de Educação, Lisboa, v. 20, n. 20, p. 81-98, ago. 2012. Disponível em: http://revistas.ulusofona.pt/index.php/rleducacao/article/view/2939. Acesso em: 12 mar. 2018.

J ENICHEN, N. M. Os padrões de competência em TIC para professores estabelecidos pela UNESCO: investigando o desejável e o provável na percepção de docentes do ensino superior de Santa Catarina para o decênio 2014-2024. 2014. Dissertação (Mestrado em Educação) - Universidade do Vale do Itajaí, Itajaí, 2014. Disponível em: https://siaiap39.univali.br/repositorio/bitstream/repositorio/1713/1/ Natalia\%20Muelle r\%20] enichen.pdf. Acesso em: 12 fev. 2018.

KENSKI, V. M. Educação e tecnologias: o novo ritmo da informação. 8. ed. Campinas: Papirus, 2012.

LEITE, G. M. S.; LIMA, F. G. C.; CALDAS, A. J 0 ensino de ciências por meio de práticas Iúdicas no recreio escolar. Revista da SBEnBio, Niterói, v. 7, p. 2722-2730, out. 2014. Disponível em: https://www.sbenbio.org.br/wordpress/wpcontent/uploads/2014/11/R0211-1.pdf. Acesso em: 1 mar. 2018.

LEMOS, A. Cibercultura: alguns pontos para compreender a nossa época. In: LEMOS, A.; CUNHA, P. (org.). Olhares sobre a Cibercultura. Porto Alegre: Sulina, 2003. p. 11-23.

LÉVY, P. Cibercultura. Rio de Janeiro: Editora 34, 1999.

LOUZANO, P.; ROCHA, V.; MORICONI, G. M.; OLIVEIRA, R. P. Quem quer ser professor? Atratividade, seleção e formação docente no Brasil. Estudos em Avaliação Educacional, São Paulo, v. 21, n. 47, p. 543-568, set./ dez. 2010. Disponível em: http://www.fcc.org.br/ pesquisa/publicacoes/ eae/arquivos/1608/1608.pdf. Acesso em: 14 mar. 2018. 
MACHADO, M. J .; KAMPFF, A. J . C. A cultura digital na edu cação básica: investigação sobre concepções, práticas e necessidades formativas. In: CONGRESSO NACIONAL DE EDUCAÇÃO, 13., 2017, Curitiba. Anais [...]. Curitiba: PUCPR, 2017. p. 1341-1356.

Disponível em: http://educere.bruc.com.br/arquivo/pdf2017/26322_14084.pdf. Acesso em: 5 mar. 2018.

MARINHO, S. P. As tecnologias digitais no currículo da formação inicial de professores da educação básica: o que pensam alunos de licenciaturas. Relatório técnico de pesquisa. Programa de Pós-graduação em Educação, Pontifícia Universidade Católica, Belo Horizonte, 2008. Disponível em:

http://portal.pucminas.br/imagedb/mestrado_doutorado/publicacoes/PUA_ARQ_ARQU 120120828101647.pdf. Acesso em: 6 jan. 2018.

MARTINEZ, R.; LEITE, C.; MONTEIRO, A. Os desafios das TIC para a formação inicial de professores: uma análise da agenda internacional e suas influências nas políticas portuguesas. Crítica Educativa, Sorocaba, v. 1, n. 1, p. 21-40, jan./jun. 2015. Disponível em: www.criticaeducativa.ufscar.br/index.php/criticaedu cativa/article/view/22/169. Acesso em: 8 mar. 2018.

MEIRINHOS, M.; OSÓRIO, A. Práticas educativas com TIC: uma proposta de ação. Revista de Estudios e Investigación en Psicología y Educación, La Coruña, n. 13, p. 120-124, 2015. Disponível em:

http://revistas.udc.es/index.php/reipe/article/view/reipe.2015.0.13.452/pdf_380.

Acesso em: 20 mar. 2017.

MELLO, D. E.; MORAES, D. A. F.; BARROS, D. M. V. Formação de professores e TIC: em busca de inovações didáticas. In: SOBRAL, M. N.; GOMES, C. M.; ROMÃO, E. (org.). Didática on-line: teorias e práticas. Maceió: EDUFAL, 2017. p. 123-142.

NERI, M. (coord.). Mapa da inclusão digital. Rio de J aneiro: FGV: CPS, 2012.

NICOLACI-DA-COSTA, A. M. (org.). Cabeças digitais: o cotidiano na Era da Informação. Rio de J aneiro: Editora PUC-Rio: Loyola, 2006.

PASSERINO, L. M. Apontamentos para uma reflexão sobre a função social das tecnologias no processo educativo. Revista Texto Digital, Florianópolis, v. 6, n. 1, p. 5877, 2010.

PRENSKY, M. Digital natives, digital immigrants. On the Orizon, Bradford, v. 9, n. 5, Oct. 2001.

SALOMON, G. Las diversas influencias de la tecnologia em el desarrolo de la mente. Infancia y Apredizaje, Madrid, v. 58, p. 143-159, 1992. Disponível em:

https://dialnet.unirioja.es/descarga/articulo/48400.pdf. Acesso em: 5 mar. 2018.

SAVIANI, D. Escola e democracia. 24. ed. São Paulo: Cortez, 1991.

SIBILIA, P. Redes ou parede: a escola em tempos de dispersão. Rio de Janeiro: Contraponto, 2012. 
SILVA, M. Sala de Aula Interativa. Rio de Janeiro: Quartet, 3a ed. 2002.

SILVA, M. Educar na cibercultura: desafios à formação de professores para docência em cursos online. Revista Digital de Tecnologias Cognitivas, São Paulo, n. 3, jan./jun. 2010. Disponível em: http://www4.pucsp.br/pos/tidd/teccogs/artigos/2010/edicao_3/3educar_na_ciberculturadesafios_formacao_de_professores_para_docencia_em_cursos_online-marco_silva.pdf. Acesso em: 12 fev. 2018.

SOUSA, R. P.; MOITA, F. M. C. S. C.; CARVALHO, A. B. G. Tecnologias digitais na educação. Campina Grande: EDUEPB, 2011.

TAPSCOTT, D. Geração digital: a crescente e irreversível ascensão da Geração Net. São Paulo: Makron Books, 1999.

WERTHEIN, J . A sociedade da informação e seus desafios. Ciência da Informação, Brasília, v. 29, n. 2, p. 71-77, maio/ago. 2000. Disponível em:

http://www.scielo.br/pdf/ci/v29n2/a09v29n2.pdf. Acesso em: 15 fev. 2018.

Recebido em: 18/11/2018

A provado em: 06/01/2019 